\title{
DEOXYSPERGUALIN DIRECTLY SUPPRESSES ANTIBODY FORMATION IN VIVO AND IN VITRO
}

\author{
Hideji Fujil, Teruyo TaKada, Kyuichi Nemoto, \\ Takumi Yamashita, Fuminori Abe, Akio FujiI \\ and TOMIO TAKEUCHI ${ }^{\dagger}$ \\ Research Laboratories, Pharmaceuticals Group, Nippon Kayaku Co., Ltd., \\ 3-31-12 Shimo, Kita-ku, Tokyo 115, Japan \\ † Institute of Microbial Chemistry, \\ 3-14-23 Kamiosaki, Shinagawa-ku, Tokyo 141, Japan
}

(Received for publication September 16, 1989)

\begin{abstract}
The effect of deoxyspergualin (DSG, NKT-01) on humoral immunity was investigated both in vitro and in vivo. DSG inhibited the primary and secondary responses to $T$ cell-dependent antigens and the response to $\mathrm{T}$ cell-independent antigens in thymic and athymic mice. However, natural antibodies in non-sensitized mice were affected less by the administration of DSG. The agent produced a dose-dependent inhibition of B cell proliferation and antibody production to lipopolysaccharide in vitro. Suppression of secondary antibody response was also shown, whenever antigen stimulation was not given, antibody production was not affected. These results suggest that DSG affects the proliferative stage of B lymphocytes in such a way as to inhibit their growth and antibody production.
\end{abstract}

Deoxyspergualin (DSG, NKT-01) an analogue of spergualin ${ }^{1)}$ has strong antitumor activity ${ }^{2)}$, and immunosuppressive activity ${ }^{3)}$. DSG administration to animals results in inhibition of cellular immune responses including allograft rejection ${ }^{4 \sim 7)}$, xenograft rejection ${ }^{8)}$, graft- $\nu s$-host disease ${ }^{9,10)}$, and delayed type hypersensitivity ${ }^{3)}$. It also has therapeutic effects on experimental animal models for autoimmune disease, which are responsible for humoral immunity ${ }^{11}$.

We have been investigating the mode of action of DSG on immunosuppressive activity. At the concentration detected following in vivo administration and therapeutic efficacy, DSG has less activity in vitro. Recently, we reported that the lower activity of DSG in vitro is due to decomposition of DSG in the culture medium ${ }^{12)}$.

This paper shows the suppressive effects of DSG on humoral immune responses against several kinds of antigens both in vitro and in vivo in BALB/c thymic and athymic mice.

\section{Materials and Methods}

Animals

$\overline{\mathrm{BALB} / \mathrm{c}}$ male mice were obtained from Charles River Japan Inc. (Kanagawa) and Shizuoka Laboratory Animals Center (Shizuoka). Athymic BALB/c (nu/nu) mice were obtained from Clea Japan Co., Ltd. (Tokyo). These mice were $6 \sim 9$ weeks old and maintained in specific-pathogen-free conditions.

\section{Antigens}

Egg albumin (EA) and bovine serum albumin (BSA; Seikagaku Kogyo, Tokyo) were dinitrophenylated using dinitrobenzenesulfonic acid (DNP-EA, 6.3 DNP groups/mol; DNP-BSA, 7.0 DNP groups/mol). Keyhole limpet hemocyanin $(\mathrm{KLH})$ was dinitrophenylated using dinitrofluorobenzene (DNP-KLH; 6.6 DNP groups/MW 50,000). DNP-lysyl-Ficoll (DNP-Ficoli, 3.0 DNP groups/MW 50,000) was prepared by dinitrophenylation of Ficoll (Nakarai Chemicals, Ltd., Kyoto), according to the procedure 
described by KLAus et al. ${ }^{13)}$. Escherichia coli lipopolysaccharide (LPS; 055; B5, Difco, Detroit, MI, U.S.A.) was dinitrophenylated in a similar fashion (DNP-LPS 2.7 DNP groups/MW 50,000).

\section{Agents and Culture Medium}

DSG (1-amino-19-guanidino-11-hydroxy-4,9,12-triazanonadecane-10,13-dione) and deoxymethylspergualin (MeDSG: 1-amino-19-guanidino-11-methoxy-4,9,12-triazanonadecane-10,13-dione) were provided by Takara Shuzo Co., Ltd. (Kyoto). Spergualins were dissolved in physiological saline and sterilized by Millipore filtration. RPMI-1640 and sodium pyruvate were purchased from Gibco (Grand Island, NY, U.S.A.), and complete serum free medium S-clone SF-H was obtained from Sanko Pure Chemical Co., Ltd. (Tokyo).

\section{Immunization}

DNP-EA or DNP-KLH were given by ip injection as an alum-precipitate ( $1 \mu \mathrm{g} /$ mouse $)$ or FREUND's complete adjuvants (FCA, $100 \mu \mathrm{g} /$ mouse). DNP-LPS and DNP-Ficoll were given by iv injection.

\section{Measurement of Anti-DNP Antibody by Enzyme-linked Immunosorbent Assay (EIA)}

EIA was carried out by a modified method of MAEKAWA and OVARY ${ }^{14)}$. Nunc Immunoplate I (Nunc, Roskilde, Denmark) was coated with DNP-BSA $(10 \mu \mathrm{g} / \mathrm{ml})$ dissolved in $0.1 \mathrm{~m}$ sodium carbonate buffer $\mathrm{pH}$ 9.6. After incubating for 2 hours at $37^{\circ} \mathrm{C}$, free-sites were blocked with $0.2 \%$ BSA. $1 / 200 \sim 1 / 2,000$ dilution of the samples were added to the plates, then washed and 1/1,000 dilution of goat anti-mouse $\operatorname{IgG}$ (Cooper Biochemical, Inc., Malvern, PA, U.S.A.) was added. After washing, 1/1,000 dilution of alkaline phosphatase-conjugate rabbit anti-goat IgG (Miles Laboratories, Inc., Elkhart, IN, U.S.A.) was added. The pipetted volume in each well was $0.1 \mathrm{ml}$ except in wells for blocking nonspecific binding where it was $0.2 \mathrm{ml}$. The plates were washed using phosphate buffered saline with $0.1 \%$ gelatin as the washing and diluting buffer. The wells were incubated for 1.5 hours at $37^{\circ} \mathrm{C}$ without coating. Finally $200 \mu \mathrm{l}$ of $p$-nitrophenyl phosphate disodium salt (Wako Pure Chemical Industries, Ltd., Osaka) in 10\% diethanolamine buffer $\mathrm{pH} 9.8$ at $0.2 \mathrm{mg} / \mathrm{ml}$ was added and incubated for 1 hour at room temperature. The absorbance of $p$-nitrophenyl moiety was measured at $405 \mathrm{~nm}$. Mouse anti-DNP-IgM monoclonal antibody for standard was purchased from Sera-lab, Ltd. (Sussex, England). Anti-DNP-IgG antibody was produced by multiple immunization of the mice with DNP-EA in FCA, and was purified from their sera on DNP-sepharose column and DEAE-cellulose column chromatography.

Immunodiffusion Assay

Anti-DNP standard and serum IgG and IgM were measured using Radial immunodiffusion (RID) kits (ICN Immunobiological, Lisle, IL, U.S.A.).

\section{Mitogenic Response to LPS In Vitro}

Mitogenic response to LPS was carried out by incubating BALB/c mouse spleen cells $\left(2 \times 10^{5} / \mathrm{ml}\right)$ with $20 \mu \mathrm{g} / \mathrm{ml}$ of LPS in RPMI-1640 supplemented with $0.5 \%$ murine serum, $1 \mathrm{~mm}$ pyruvate and 2-mercaptoethanol $25 \mu \mathrm{M}$ for 72 hours. Four hours before harvest, $1 \mu \mathrm{Ci}$ of $\left[{ }^{3} \mathrm{H}\right]$ thymidine $\left.\left({ }^{3} \mathrm{H}\right] \mathrm{TdR}\right)$ $(15.5 \mathrm{mCi} / \mathrm{mmol}$, New England Nuclear, Boston, MA, U.S.A.) was added to each well.

\section{Antibody Production In Vitro}

Antibody production to DNP-LPS was performed by incubating BALB/c mouse spleen cells $\left(5 \times 10^{6} / \mathrm{ml}\right)$ with $20 \mu \mathrm{g} / \mathrm{ml}$ of DNP-LPS in complete serum free medium, S-clone SF-H for 120 hours. Anti-DNP-IgM in the supernatant was measured by EIA.

BALB/c mice were primed for secondary response by giving $100 \mu \mathrm{g}$ of DNP-KLH with FCA. Six to eight months later, the primed cells were obtained as spleen cells and cultured in complete serum free medium $\left(5 \times 10^{6}\right.$ cells $\left./ \mathrm{ml}\right)$ with or without DNP-KLH for 120 hours. 


\section{Results}

Effect of DSG on Antibody Response to T Cell-Dependent (TD) Antigens

DNP-specific IgG concentrations in plasma increased in mice following immunization with DNP-EA alum of TD antigen. When various doses of DSG were given to the immunized mice daily for 14 days from day 0 to 13, the increase in IgG levels in plasma was reduced dose-dependently (Table 1). DSG at $3 \mathrm{mg} / \mathrm{kg} /$ day suppressed over $95 \%$ of the IgG response. When the DSG administration was carried out from the day 10 to 23 instead of day 0 to 13 , an increase in the anti-DNP-IgG levels in plasma was similarly inhibited (Fig. 1).

The effect of DSG and MeDSG on the in vitro secondary response to DNP-KLH was examined following stimulation with $10 \mathrm{ng} / \mathrm{ml}$ of the antigen, both DSG and MeDSG exhibited marked inhibition of anti-DNP-IgG and IgM production (Fig. 2). The $\mathrm{IC}_{50}$ values of the IgM response in terms of concentration of DSG and MeDSG were 1.0 and $0.017 \mu \mathrm{g} / \mathrm{ml}$, respectively. Both DSG and MeDSG inhibited the $\mathrm{IgG}$ response and $\mathrm{IC}_{50}$ values were 0.006 and $0.004 \mu \mathrm{g} / \mathrm{ml}$, respectively (data not shown). In contrast, unless DNP-KLH primed cells were stimulated by the antigen, spergualins did not affect either IgM or IgG antibody production.

Effect of DSG on Responses to TI-I and TI-II Antigens

The effect of DSG on responses of antibody formation to DNP-LPS (TI-I antigen) and DNPFicoll (TI-II antigen) were examined. BALB/c mice were immunized with DNP-LPS or DNP-Ficoll on

Fig. 1. Effect of DSG on anti-DNP-IgG production.

$\mathrm{BALB} / \mathrm{c}$ mice were given alum-preciptated DNP-EA on day 0 , and at the dose of $3 \mathrm{mg} / \mathrm{kg}$ of DSG was given from day 10 to $23(\bullet)$ or saline (o).

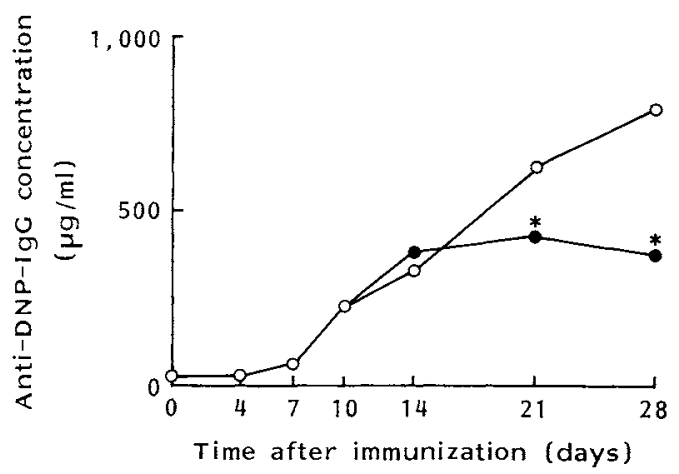

Significant difference from control by $\mathrm{t}$-test. ${ }^{*} P<0.01$.

Table 1. Effect of various doses of DSG on the response to TD antigen of DNP-EA.

\begin{tabular}{ccc}
\hline $\begin{array}{c}\text { Daily dose } \\
(\mathrm{mg} / \mathrm{kg})\end{array}$ & $\begin{array}{c}\text { Anti-DNP IgG concentration } \\
(\mu \mathrm{g} / \mathrm{ml} \pm \mathrm{SD})\end{array}$ \\
\hline None & $544 \pm 70$ & $(0)^{\mathrm{a}}$ \\
0.1 & $486 \pm 49$ & $(11)$ \\
0.3 & $362 \pm 41^{*}$ & $(33)$ \\
1.0 & $76 \pm 42^{*}$ & $(86)$ \\
3.0 & $17 \pm 16^{*}$ & $(97)$ \\
10.0 & $4 \pm 2^{*}$ & $(99)$ \\
\hline
\end{tabular}

Groups $(n=5)$ of $\mathrm{BALB} / \mathrm{c}$ mice were given $1 \mu \mathrm{g}$ alum-precipitated DNP-EA (day 0) for the immunization and various doses of DSG on day 0 through 13. The anti-DNP IgG level in plasma samples, which were collected on day 14, was measured by EIA.

Significant difference from control by t-test. $* P<0.01$.

a Suppression percent compared to control response.

Fig. 2. Effect of spergualins on secondary antibody production to DNP-KLH in vitro.

DSG (•), MeDSG (O), control (ム), spontaneous $(\triangle)$.

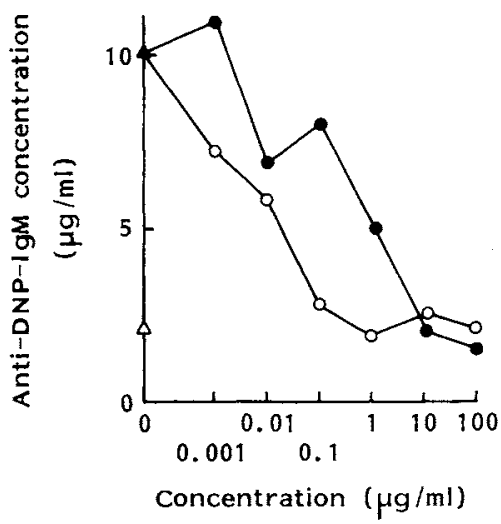

The primed spleen cells $\left(1 \times 10^{6} /\right.$ well $\left./ 200 \mu 1\right)$ were cultured with $0.01 \mu \mathrm{g} / \mathrm{ml}$ of DNP-KLH. 
Fig. 3. Effect of DSG on the response to TI antigens.

(A)

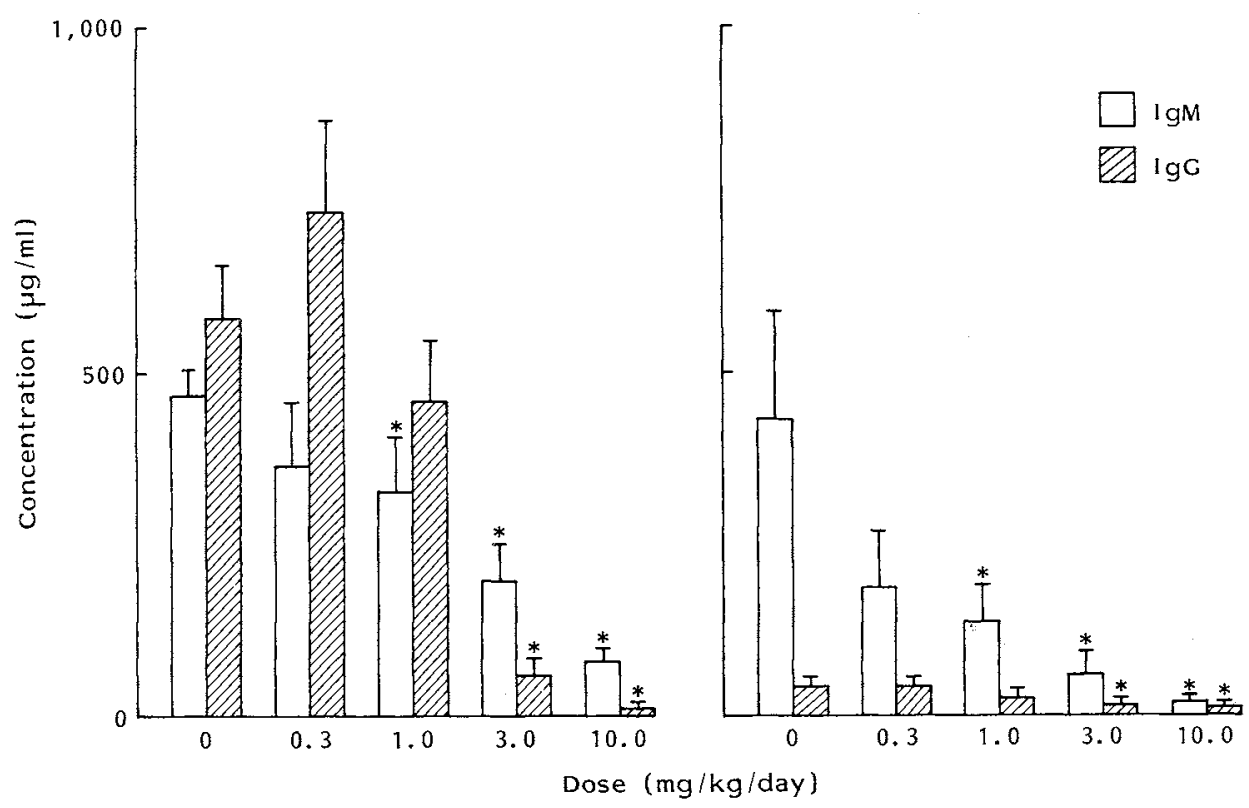

BALB $/ \mathrm{c}$ mice were given $50 \mu \mathrm{g}$ of DNP-LPS (TI-I antigen) (A) or DNP-Ficoll (TI-II antigen) (B) on day 0 , and various doses of DSG from day 0 to 7 . Plasma samples were collected on day 4 and 8 via retro-orbital plexus puncture, and EIA was carried out.

Significant difference from control by t-test.

${ }^{*} P<0.01$.

Table 2. Effect of DSG on the response to DNP-LPS in athymic mice.

\begin{tabular}{|c|c|c|c|c|c|c|}
\hline \multirow{3}{*}{$\begin{array}{c}\text { Daily } \\
\text { dose } \\
(\mathrm{mg} / \mathrm{kg} / \text { day })\end{array}$} & \multicolumn{6}{|c|}{ Anti-DNP antibody concentration $(\mu \mathrm{g} / \mathrm{ml})$} \\
\hline & \multicolumn{3}{|c|}{ Day 4} & \multicolumn{3}{|c|}{ Day 8} \\
\hline & \multicolumn{2}{|l|}{$\operatorname{IgM}$} & $\operatorname{IgG}$ & \multicolumn{2}{|l|}{$\operatorname{IgM}$} & $\mathrm{IgG}$ \\
\hline Saline & $424 \pm 28$ & $(0)^{a}$ & $81 \pm 14 \quad(0)$ & $224 \pm 23$ & $(0)$ & 1,318 上 189 \\
\hline 1.0 & $360 \pm 24 * *$ & (15) & $48 \pm 20^{*} \quad(41)$ & $147 \pm 19^{* *}$ & (34) & $1,059 \pm 188$ \\
\hline 3.0 & $235 \pm 39^{* *}$ & (45) & $43 \pm 6 * *(47)$ & $99 \pm 9 * *$ & $(56)$ & $555 \pm 323^{* *}(58)$ \\
\hline 10.0 & $84 \pm 29 * *$ & $(80)$ & $30 \pm 12^{* *}(63)$ & NT & & $81 \pm 22 * *(94)$ \\
\hline
\end{tabular}

Groups $(n=5$ ) of BALB/c $n u / n u$ mice were given $50 \mu \mathrm{g}$ of DNP-LPS (day 0 ) and various doses of NKT-01 daily from day 0 to 7 . Plasma samples were collected on day 4 or 8 via retro-orbital plexus puncture, and EIA was carried out.

Significant difference from control by t-test. ${ }^{*} P<0.05$, ${ }^{* *} P<0.01$.

NT: Not tested.

a Suppression percent compared to control response.

day 0 and given various doses of DSG from day 0 to 7 . The responses to DNP-LPS or DNP-Ficoll were assayed by measurement of anti-DNP-IgM or IgG concentrations in the plasma obtained from the above immunized mice on day 4 and 8. Both anti-DNP-LPS IgM and IgG concentration in the plasma responses were reduced dose-dependently (Fig. 3). The IgM response following DSG administration at doses of 1 , 3 and $10 \mathrm{mg} / \mathrm{kg} /$ day caused 30,57 and $83 \%$ suppression compared to controls by the 4 th day after 
Fig. 4. Effect of DSG on the response to LPS induced blastogenesis in vitro.

DSG (•), MeDSG (०).

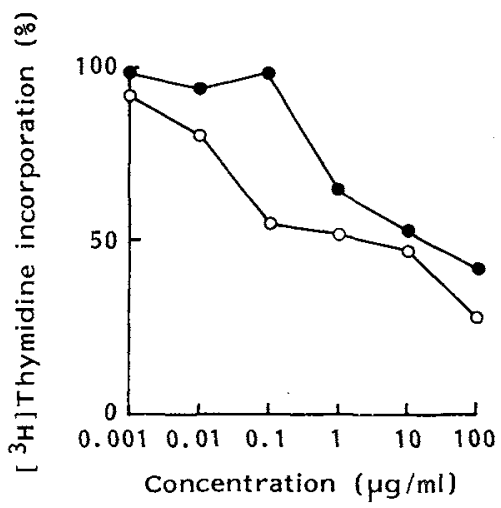

BALB/c spleen cells $\left(2 \times 10^{5} /\right.$ well $\left./ 200 \mu \mathrm{l}\right)$ were cultured with $20 \mu \mathrm{g} / \mathrm{ml}$ of LPS for 72 hours. Mean control dpm $=162,802 \pm 6,173$.

immunization, while the IgG response was reduced 20,90 and $98 \%$ by day 8 . There were no discernible differences in the susceptibility of the DNP-LPS response in $n u / n u$ and $n u /+$ mice. Both $\operatorname{IgM}$ and IgG responses to DNP-Ficoll were also reduced dose-dependently, and 1,3 and $10 \mathrm{mg} / \mathrm{kg} /$ day of DSG caused 68,85 and $96 \%$ suppression of the IgM response (day 8 ), respectively. DSG markedly reduced the response to DNP-LPS and DNP-Ficoll.

To examine the direct effect of DSG on B cells, $n u / n u$ mice were immunized with DNP-LPS and given various doses of DSG from day 0 to 7 . Both IgM and IgG responses to DNP-LPS were markedly reduced dose-dependently in $n u / n u$ mice by DSG administration (Table 2). DSG at the dose of $3 \mathrm{mg} / \mathrm{kg} /$ day caused $40 \sim 60 \%$ suppression of both Ig responses. This result indicates that DSG has the capability to directly suppress the B cell function, not via $\mathrm{T}$ cells.

The in vitro effect of DSG and MeDSG on mitogenic response to LPS was assessed. DSG and MeDSG inhibited the mitogenic response over the concentration of 1.0 to $0.1 \mu \mathrm{g} / \mathrm{ml}$. The maximum inhibition observed was $60 \sim 70 \%$ suppression relative to control levels at a dose of $100 \mu \mathrm{g} / \mathrm{ml}$ (Fig. 4).

The effect of DSG and MeDSG on IgM production to DNP-LPS was also examined. These compounds inhibited the response dose-dependently (Fig. 5). DSG and MeDSG exhibited marked inhibition of the response over 0.1 and $0.01 \mu \mathrm{g} / \mathrm{ml}$, respectively. The $\mathrm{IC}_{50}$ values of DSG and MeDSG were 0.17 and $0.026 \mu \mathrm{g} / \mathrm{ml}$, respectively.
Fig. 5. Effect of spergualins on antibody production to DNP-LPS in vitro.

DSG (•), MeDSG (O), control (४), spontaneous

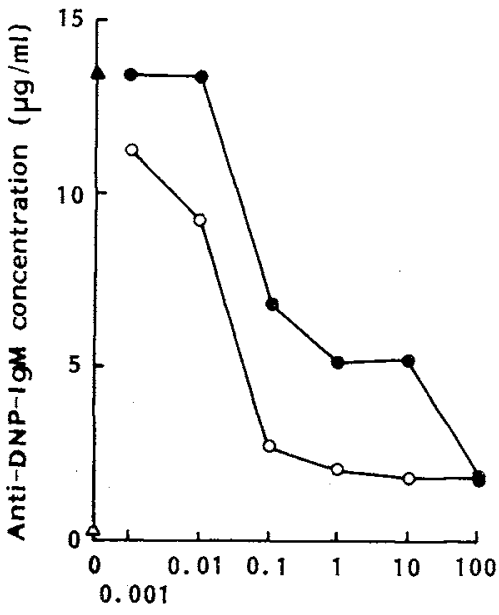

Concentration $(\mu \mathrm{g} / \mathrm{ml})$

BALB $/ \mathrm{c}$ spleen cells $\left(1 \times 10^{6} /\right.$ well $\left./ 200 \mu \mathrm{l}\right)$ were cultured with $20 \mu \mathrm{g} / \mathrm{ml}$ of DNP-LPS for 120 hours. Anti-DNP-IgM were measured by EIA.

Table 3. Effect of DSG on total IgM and IgG concentrations in serum.

\begin{tabular}{lccc}
\hline Immunize & DSG & $\begin{array}{c}\text { IgG concentration } \\
(\mu \mathrm{g} / \mathrm{ml})\end{array}$ \\
\hline Normal & - & $1,000 \pm 80$ & $(100)^{\mathrm{b}}$ \\
Normal & + & $1,090 \pm 40$ & $(109)$ \\
DNP-EA & - & $2,280 \pm 310^{*}$ & $(228)$ \\
DNP-EA & + & $940 \pm 40$ & $(94)$ \\
\hline
\end{tabular}

Groups $(n=5)$ of BALB/c mice were given $3 \mathrm{mg} / \mathrm{kg}$ of DSG from day 0 through to 14. Plasma samples were collected on day 14 , bleeding via cardiac puncture and then RID was carried out.

Significant difference from control by t-test. ${ }^{*} P<0.01$.

a Mice had received $100 \mu \mathrm{g}$ of DNP-EA with FCA on day 0 .

b Percentage of control response. 


\section{Effect of DSG on Total IgM and IgG in Plasma}

Non-immunized or immunized mice were treated daily with saline or $3 \mathrm{mg} / \mathrm{kg} /$ day of DSG for a 14-day-period, and the total plasma IgG and IgM concentration were measured on day 15 by RID. The total IgG in the immunized mice increased, but the levels in DSG-administered mice did not. In contrast, the total IgG of the non-immunized mice was not affected by DSG, and the total IgM decreased slightly (Table 3). This indicates that DSG has a suppressive effect on antibody production which is induced by antigen stimulation, but non-stimulated antibody production (natural antibody) is less sensitive to DSG. Histological examination of spleen specimens obtained from non-immunized mice did not show a decrease in plasma cell number even after 14 days administration of DSG.

\section{Discussion}

DSG shows little in vitro immunosuppressive activities at the therepeutic concentration found following in vivo administration. Recently we reported that there are some technical problems with in vitro experiments: 1) DSG is hydrolyzed in the culture medium during incubation causing loss of activity ${ }^{12)}$. 2) DSG is oxidized by amine oxidase in fetal calf serum, and the oxidized products ${ }^{15}$ have cytotoxic effects on lymphocytes and leukemia cells, but the fact has no relation to in vivo activities. The in vitro effects were examined using a stable analogue, MeDSG, and in culture media which have no amine oxidase activity. Spergualins exhibit suppressive effects on LPS induced blastogenesis and antibody production to TD and TI antigens in vivo ${ }^{16)}$ and in vitro indicating that spergualins affect the proliferation and differentiation of $\mathrm{B}$ cell lineage directly. Unless antigen stimulation was given, antibody production or serum titer of natural antibody was not affected.

IgM and IgG antibody responses to TI-I in nude mice were inhibited significantly, which indicates that DSG directly affects B cells. The B cell population can be divided into two groups using CBA/N mice ${ }^{17}$. One $B$ cell population which is activated by TI-I and TI-II antigens expresses a surface markers Lyb 5, the other insensitive to TI-II antigen is devoid of some surface marker such as Lyb 5. The responses to TI-I and TI-II antigens were inhibited by DSG. This indicates that DSG affects both Lyb $5^{+}$and Lyb $5^{-} \mathrm{B}$ cells.

Fourteen days administration of DSG inhibited the increase of total immunoglobulins in sensitized mice, but was not so effective in normal mice. It has been reported that the life span of plasma cells is only a few days ${ }^{18)}$, half lives of $\operatorname{IgG}$ are $6 \sim 8$ days, and $\operatorname{IgM}$ is shorter than $\operatorname{IgG}^{19,20)}$. These results indicate that DSG has a less direct effect upon plasma cells and upon the generation of plasma cells from $B$ lymphocytes in a steady state where antigen stimulation is absent.

It was reported that cyclosporin A (CYA) had a suppressive effect on antibody production of Lyb $5^{+} \mathrm{B}$ cells which were stimulated by TI-II antigens directly, but Lyb $5^{-}$B cells had enhanced antibody production or not affected ${ }^{21,22)}$. Spergualins suppressed antibody production following stimulation by both TI-I and TI-II antigens. The effects of spergualins were obviously different from CYA.

In conclusion DSG has an anti-proliferative effect on proliferating cells, such as leukemia cells ${ }^{2)}$ and lymphocytes ${ }^{12)}$. The immunosuppressive effect of DSG on humoral immunity was due to the antiproliferative effect or to the inhibitory effect on B cell maturation. However DSG has little effect on plasma cells and non-stimulated B lymphocytes which don't proliferate potently.

\section{References}

1) Takeuchi, T.; H. Innuma, S. Kunimoto, T. Masuda, M. Ishizuka, M. Takeuchi, M. Hamada, H. Naganawa, S. KoNDO \& H. UMEZAWA: A new antitumor antibiotic, spergualin: Isolation and antitumor activity. J. Antibiotics 34: $1619 \sim 1621,1981$

2) Iwasawa, H.; S. Kondo, D. IKeda, T. Takeuchi \& H. Umezawa: Synthesis of (-)-15-deoxyspergualin and (-)-spergualin-15-phosphate. J. Antibiotics 35: 1665 1669, 1982

3) Nemoto, K.; M. Hayashi, F. Abe, T. Nakamura, M. Ishizuka \& H. Umezawa: Immunosuppressive activities of 15-deoxyspergualin in animals. J. Antibiotics 40: $561 \sim 562,1987$ 
4) Ochiai, T.; S. Hori, K. Nakajima, M. Nagata, T. Asano, K. Isono \& H. Umezawa: Prolongation of rat heart allograft survival by 15-deoxyspergualin. J. Antibiotics 40:249 250, 1987

5) Suzuki, S.; M. Kanashiro \& H. AmemiYa: Immunosuppressive effect of a new drug, 15-deoxyspergualin, in heterotopic rat heart transplantation: In vivo energy metabolic studies by ${ }^{31} \mathrm{P}-\mathrm{NMR}$ spectroscopy. Transplant. Proc. 19: 3982 3984, 1987

6) SuZuKI, S.; M. KANAShiro \& H. AmEMIYA: Effect of a new immunosuppressant, 15-deoxyspergualin, on heterotopic rat heart transplantation, in comparison with cyclosporine. Transplantation $44: 483 \sim 487,1987$

7) ITOH, J.; T. TAKEuchi, S. Suzuki \& H. AmEMiYA: Reversal of acute rejection episodes by deoxyspergualin (NKT-01) in dogs receiving renal allografts J. Antibiotics 41: 1503 1505, 1988

8) Walter, P.; U. Bernhard, G. Seitz, G. Dickneite \& H. H. Sedlacek: Xenogeneic heart transplantation with 15-deoxyspergualin. Prolongation of graft survival. Transplant. Proc. 19: 3993 3994, 1987

9) Nemoto, K.; M. Hayashi, H. Fuji, J. Ito, T. Nakamura, T. Takeuchi \& H. Umezawa: Effect of 15-deoxyspergualin on graft- $v$-host disease in mice. Transplant. Proc. 19: 3985 3986, 1987

10) Nemoto, K.; J. Ito, M. Hayashi, F. Abe, Y. Ohtaka, T. Nakamura, T. Takeuchi \& H. Umezawa: Effects of spergualin and 15-deoxyspergualin on the development of graft-versus-host disease in mice. Transplant. Proc. 19: $3520 \sim 3521,1987$

11) Nemoto, K.; M. Hayashi, Y. Sugawara, J. Ito, F. Abe, T. Takita, T. Nakamura \& T. Takeuchi: Biological activities of deoxyspergualin in autoimmune disease mice. J. Antibiotics 41: 1253 1259, 1988

12) Fuji, H.; T. TAKada, K. Nemoto, F. AвE \& T. TAkeuchi: Stability \& immunosuppressive activity of deoxyspergualin in comparison with deoxymethylspergualin. Transplant. Proc. 21: $3471 \sim 3473,1989$

13) Klaus, G. G. B.; J. M. Phillips, J. H. Humphrey, D. W. Dresser \& A. M. Cross: The immunological properties of haptens coupled to thymus-independent carrier molecules. IV. The IgG response to dinitrophenylated Ficoll. Eur. J. Immunol. 6: 429 433, 1976

14) MaekaWA, S. \& Z. OvarY: Correlation of murine anti-dinitrophenyl antibody content as determined by ELISA, passive cutaneous anaphylaxis and passive hemolysis. J. Immunol. Methods 71: $229 \sim 239,1984$

15) Kuramochi, H.; M. Hiratsuka, S. Nagamine, K. Takahashi, T. Nakamura, T. Takeuchi \& H. Umezawa: The antiproliferative action of deoxyspergualin is different from that induced by amine oxidase. J. Antibiotics 41 : $234 \sim 238,1988$

16) Makino, M.; M. Fujiwara, H. Watanabe, T. Aoyagi \& H. Umezawa: Immunosuppressive activities of deoxyspergualin. II. The effect on the antibody responses. Immunopharmacology 14: 115 122, 1987

17) SCHER, I.: The CBA/N mouse strain: An experimental model illustrating the influence of the $\mathrm{X}$-chromosome on immunity. Adv. Immunol. 33: 2 71, 1982

18) Makinodan, T. \& J. F. Albright: Proliferative and differentiative manifestations of cellular immune potential. Prog. Allergy 10: 1 36, 1967

19) BAzIN, H. \& F. MALET: The metabolism of immunoglobulin classes in irradiated mice. Immunology 17: $354 \sim 365$, 1969

20) Vieira, P. \& K. RAJeWSKY: The bulk of endogenously produced $\operatorname{IgG}_{2 \mathrm{a}}$ is eliminated from the serum of adult G57BL/6 mice with a half-life of $6 \sim 8$ days. Eur. J. Immunol. 16: 871 $\sim 874,1986$

21) Shidani, B.; J.-H. Colle, I. Motta \& P. Truffabachi: Effect of cyclosporin A on the induction and activation of $B$ memory cells by thymus-independent antigens in mice. Eur. J. Immunol. 13: 359 363, 1983

22) Kunkel, A. \& G. G. B. Klaus: Selective effects of cyclosporin A on functional B cell subsets in the mouse. J. Immunol. 125: 2526 2531, 1980 